\title{
Innovation for Sustainability: Overcoming the Productivity of the Sugar-and-Ethanol Industry's Conventional System
}

\author{
André Pereira de Carvalho', José Carlos Barbieri²
}

\begin{abstract}
The article's objective is to analyze a process of technological innovation incorporation in the realm of organic agriculture which, as per legal and conceptual definition, should take into consideration the economic, social and environmental aspects according to the proposals of sustainable development. This article presents the results of a case study carried out at Native Alimentos Orgânicos Ltd. , a Brazilian company producing organic sugar and ethanol with an exporter profile and responsible for the world's largest organic agriculture project. The organic production system developed by the company demanded important innovation in the agricultural and industrial areas. The study shows that the choice for innovations that respond simultaneously to economic, environmental and social issues, besides being viable, is essential for the Brazilian sugar to access markets of developed countries. Thus the case shows that it is possible to innovate with profit and social and environmental concern simultaneously.
\end{abstract}

Keywords: innovation; sustainability; sustainable agriculture; organic products.

\footnotetext{
I São Paulo Business Administration School of Fundação Getulio Vargas (FGV-EAESP), Department of Production and Industrial Operations Administration. Avenida Nove de Julho 2029, Bela Vista, São Paulo, SP, 0 I 3 I3-902, Brazil. Tel: +55 (I I) $3799-7780$. E-mail: andre.carvalho@fgv.br

2 São Paulo Business Administration School of Fundação Getulio Vargas (FGV-EAESP), Department of Production and Industrial Operations Administration. Avenida Nove de Julho 2029, Bela Vista, São Paulo, SP, 0I 3I 3-902, Brazil. Tel: +55 (I I) $3799-7780$.

E-mail: jose.barbieri@fgv.br
} 


\section{Introduction}

The article's objective is to analyze a process of technological innovation incorporation in the realm of organic agriculture which, as per legal and conceptual definition, should take into consideration the economic, social and environmental aspects according to the proposals of sustainable development.

This article presents the results of a case study carried out at Native Alimentos Orgânicos Ltd. , a Brazilian company producing organic sugar and ethanol with an exporter profile and responsible for the world's largest organic agriculture project. The organic production system developed by the company demanded important innovation in the agricultural and industrial areas, such as the use of biological pest and spontaneous plants control techniques, green fertilizers in rotation with the growing of leguminous species to increase fixation of nutrients in the soil, new devices in the agricultural machinery and equipment to avoid soil compacting, among others.

We will initially discuss the concept of sustainable development and of sustainable agriculture, the controversial role of technological innovation in regards to the social and environmental issues, a summary of the regulatory framework established for organic agriculture in Brazil, and the research methodology.

\section{Sustainable Development's Challenges}

The conversations about sustainable development face continuous controversy and it's not the purpose of this article to enter this endless debate. The recent origins of this concept are related to the debates about the planet's environmental degradation and the serious social problems observed everywhere, including in developed countries.

At the UN Conference for the Human Environment, which took place in Stockholm in 1972, there was this firm idea that the taking care of the environment is fundamental for a durable social and economic development and that the development processes should be careful not to dilapidate the bases of development. This idea eventually became the core of the sustainable development concept which would take flight after the World Commission on Environment and Development report known as Our Common Future. In the report one finds the definition for sustainable development as it is known worldwide, i.e., "sustainable development is that which meets the needs of the present without compromising the possibility of future generations to meet their own needs" (WCED, 1991, p.46). As an overall idea, no one can be against it for it's a declaration of good intentions, but the problem starts when one tries to understand and put the concept into action. Much criticism and objections were made such as that of Lelé (1991) when the expression had not yet become popular.

Among the uncountable proposals to make the sustainable development concept effective in the field of business organizations, the most successful is that which considers it the confluence of social, environmental and economic issues. Within this perspective one understands that the company is contributing to sustainable development when its performance generates positive outcomes in economic, social and environmental terms, and the management model that best translates this idea is known as the Tipple Bottom Line (TBL) created by John Elkington in his book, Cannibals with a Fork (ELKINGTON, 200I).

Despite the unduly use that will always occur and of fierce criticism, as Norman \& MacDonald (2004) have warned, it is a fact that, when well applied, the idea of TBL becomes a suitable medium for companies to give their contribution to the development in that which they're accountable for: guiding their products and services and their activities and operations so as to obtain net outcomes in the three sustainability dimensions mentioned above. Within this context, a critical aspect refers to the role of innovation in building this new way of managing companies. As we will see ahead, there are serious doubts and diverse questioning on the theme but there are also great opportunities for the achievement of a legitimate approach to innovation based on the TBL model.

\section{Innovation and Sustainability}

Innovation is the watchword in the corporate environment, as it can be seen in renowned authors of Management, Economics, Engineering and other areas. Innovate or disappear became a kind of business slogan. And it couldn't be different; all that we see around us are in some way the outcomes of innovation, even pollution which disturbs us. That is why the relation between innovation and sustainable development is one of the issues which mostly raise conflicting opinions. 
As a matter of fact, in the origin of this movement one finds criticism to certain successful innovations such as that made by Rachel Carson in her book Silent Spring, written in 1962, relating to DDT (CARSON 2002), considered today one of the world's environmental movement landmarks. CFC was also considered a successful innovation until it was discovered that in the stratosphere it destroys the ozone layer which is in charge of protecting living beings from the UV rays. A study conducted by the European Environment Agency named Late lessons on early warnings (AEE, 200I) shows different innovations that right from the start presented some trace of problem for the environment or human health but were not taken into account until they became serious problems demanding rigorous actions from the public power.

Opinions on this matter diverge on extremes, on one hand those who believe that the scientific and technological advance will solve the problems, as in fact they have resolved many already; the air of large cities would be unbreathable if it weren't for the technological innovations which allow capturing and treating pollutants before launching them in the atmosphere. On the opposite side are those who believe that more of science and technology will not solve the problems they created, it would be more of the same. Both are totally missing the point. One should recognize that part of the environmental and social degradation is in fact associated to the innovation processes, however much of the welfare that humanity enjoys today, such as increased longevity practically everywhere, is also thanks to innovations. That is why in the mentioned report, WCED (I99I) included among the objectives of sustainable development oriented practices, the need to reorient technology and manage the risks, including the environment and the economy in the decision making process. In other words, innovations are essential elements to the sustainable development process. The question is how to make them stop playing a dubious role vis-à-vis the environment and the well being of humans, and start to effectively contribute towards achieving sustainable development objectives, which means contribute with the net results in the three dimensions mentioned above.

Considering only the environmental dimension, Shrivastava (1995), on a seminal paper about the theme, understands as environmental technologies the production equipment, methods and procedures, product designs and product distribution mechanisms that conserve energy and natural resources. These technologies involve material elements such as equipment to control pollution and measurement instruments, as well as operating methods, such as waste management practices and guidelines to create responsible approaches on the project of products, manufacture, environmental management, etc. Environmental technology innovations thus refer to equipment, operating methods and management orientation which conserve energy and natural resources. Kemp and Arundel (1998) understand environmental technology innovation as the processes, techniques, systems and new or modified products that help reduce environmental damage and may be of the following types: pollution control technologies, pollution cleaning technologies to remediate damages occurred, waste management technology, clean technology in the production processes, recycling technology and clean products or products with low environmental impact during their life cycle. Such typology emphasizes innovations whose explicit purpose is that of helping reduce environmental damages and is therefore a restricted concept since it considers only two of the sustainable development dimensions, the economic and the social which would be an eco-efficiency approach according to Picture I. Innovations which meet only the social and environmental dimensions are also restricted and in the business environment might not even be considered. Even social technologies, which are transforming technical and methodological solutions, developed and applied in an interaction with the population which uses it to promote this population's social inclusion and life condition improvements (ITS, 2004), also need to address the economic dimension, such as cost and quality, qualifying conditions to fight for competitive markets.

According to the TBL model, innovations should bring positive contributions to the three dimensions of sustainability in areas in which they are applicable, be it for services, manufacture, agriculture, mining, etc; innovations which bring the company favorable economic results and environmental enhancement, but with unemployment or degradation of a community's life conditions they wouldn't fit this model. For example, innovations in planting equipment and techniques that allow harvesting sugar cane without the burning, benefit the environment since they avoid CO2 emissions, 
preserve biodiversity and generate biomass to provide energy and soil recovery. However, these cut the jobs of people that have no other qualification than that of cutting sugarcane, therefore increasing the poverty we already have too much of. According to Borch (2007) the TBL model applied to the agriculture and cattle raising activities would involve (i) economic considerations, concerning the profitable and healthy production of plants and animals, as well as human resources and knowledge; (ii) environment and landscaping considerations which address the consequences to the physical environment , to landscape and natural values' management, including water resources and high quality of the habitats and increase of recreational values; and (iii) social considerations, involving the role of agriculture in rural development, self sufficiency, quality of life, social stability and rural economy. This author reminds us that the three "bottom lines" should not be seen as independent agendas for they overlap, generating new concepts and interfaces according to Elkington's expression. The overlapping Borch speaks about is based on Elkington (200I), but it is nothing more than the intersections of the three sustainability dimensions presented in Picture I.

Applying the WCED (1991) definition of sustainable development for agriculture, showed at the beginning of this text, one may say that sustainable agriculture is the one producing food and raw-materials to meet the basic needs of the current generation maintaining the ecosystems' vitality for future generations to meet their own needs. It is an agriculture that aims at producing healthy food and quality raw materials respecting the conditions of the environment so it can continue to be productive in time and improving the life conditions of rural producers and workers. In other words and paraphrasing Maurice Strong, Secretary of the WCED, it is an economically efficient, ecologically prudent and socially fair agriculture (Apud SACHS; 1993).

The concept of sustainable agriculture demands innovations that may simultaneously respond to the three dimensions of sustainability which, expressed in another form, requires net results in the three sustainability dimensions. Innovations in the field of organic agriculture should necessarily contemplate the three dimensions of sustainability for it to be considered a manner of practicing sustainable agriculture. As we will see ahead, this requirement was fully embraced by the Brazilian legislation.

\section{Organic Food: Definition and Market}

The expression organic agriculture refers to agricultural and cattle derived products produced in a specific manner, featuring a production system distinct from conventional agriculture, be it traditional or modern. In Brazil the regulatory framework for organic agriculture was established by Law no. 10831, December 23 2003. According to this law,

An organic agriculture and cattle raising production system is that where specific techniques are adopted by optimizing the use of the natural and social and economic resources available, as well as the respect to the cultural integrity of rural communities. It aims at economic and ecological sustainability, maximizing social benefits, minimizing dependency on non- renewable energy, employing, as far as possible, cultural, biological and mechanical methods instead of synthetic materials, eliminating the use of GMOs and ionizing radiations, in any of the phases of production, processing, storing, distribution and commercialization process in addition to environmental protection (BRASIL, 2003, art. $\left.\right|^{\text {st }}$ )

As one may observe, the Brazilian legislation includes organic agriculture in the concept of sustainable agriculture as recently defined.

In 2007 the world organic food market reached US\$ 46 billion, corresponding to about $\mathrm{I} \%$ of the total market which takes into account conventional and organic food products. The organic segment's total sales are concentrated in Europe and North America. Summing USA, Germany, United Kingdom, France, Italy and Switzerland they correspond to over $75 \%$ of the world organic food sales (IFOAM, 2009). All over the world there are 32.2 million hectares cultivated with organic production certification, in the hands of over 600 thousand producers spread throughout 120 countries circa. These areas are concentrated in Oceania (38\%), Europe (24\%) and Latin America (20\%), and in the latter region and in Africa one currently observes the major expansion of certified areas. 
The three countries with the largest extension of certified agricultural lands are: Australia (12 million hectares), Argentina (2.8 million hectares) and Brazil ( 1.8 million hectares). However, one should take into consideration that the certified areas in Argentina are mostly extensive pasture land (IFOAM, 2009).

Darolt (2002, p.196) declares that "[...] growers who have been working longer with organic agriculture tend to adopt a larger number of conservation practices.", but at the same time in which the segment gains major projection and demand, the annual production growth has brought up questionings as to the sector's capacity of gaining scale and growing sustainably. Nonetheless, Norman Borlaug, father of the green revolution and winner of the Nobel Peace Prize, is a recognized advocate of the use of synthetic fertilizers to guarantee productivity increase. He says that the idea that organic agriculture is more environmentally friendly than the conventional one is "ridiculous", and explains: organic agriculture achieves lower productivity than the conventional one and therefore it requires larger crop areas to meet the same demand for food, increasing the pressure on forest areas (THE ECONOMIST, 2006). This argument is based on the idea that organic agriculture is stagnated or delayed agriculture, in terms of technological innovation. This misunderstanding makes the case study reported in this article even more representative: that of Native, Organic Foods.

\section{Research Methodology}

This paper is to be included in the field of case studies and its design is based on Yin (1994) and Eisenhardt (1989). They assert that this strategy is well used by researchers who try to respond to questions such as "how" and "why", relative to phenomena referring to contemporary facts, which occur in contexts of little possibility of control over the studied events. In this paper we use an interpretative approach, i.e., the object matter of the case study is the understanding of "how" innovation contributes to the consolidation of a corporate sustainability model. Data collection takes place by raising secondary data about the conventional and organic sugar exporting market and by semi structured interviews with the entrepreneurs of the analyzed company, Native Organic Food Ltd. (Native). To build the Native case interviews were made with:
Fernando Alonso - Organic Products and Exports Manager.

Along this presentation, data with no citation refer to information collected in the interviews with the company's representatives. In sight of the access restrictions to official data on organic products' production and international trade, the estimates presented by the interviewees about production and mainly about the volume of exports and of international markets have a major importance in this research work. When secondary data - that could be compared to data provided by the interviewees - were not obtained, these estimates were taken on as the best information available to apply in the cases' analysis. Following Yin's (1994) recommendations, issues supporting the case description in this paper were divided into the following blocks: global organic sugar market and Native's share; the choice for organic production; the innovations in the sugarcane production process; the opportunities and challenges perceived by the entrepreneur.

\section{Case Study: Native Alimentos Orgânicos Ltd.}

The Balbo family started its activities in the sugar and ethanol business in 1946, in the city of Sertãozinho (SP BR), with the creation of the Usina Santo Antonio (Santo Antonio Mill). In 1956 the family acquired the Usina São Francisco (São Francisco Mill) $20 \mathrm{~km}$ away from the first industrial unit. One may say that the beginning of the organic production project took place in 1986, in a still not premeditated manner when the Usina São Francisco started the Green Sugarcane Project, with the purpose of developing a productive process that could do without the burning of the crop for its harvest.

The Native brand was launched in 1998 to represent the philosophy of the Green Sugarcane Project in the organic products' segment. Organic sugar was the basis for the first product line whose main customers are the food industries of the USA and Europe which resale the packaged product with their own brands. At the start of this decade, Native started to diversify its operation and get closer to end customers, searching to consolidate its brand as an organic products' reference with the end consumer. The company launched a line of breakfast products - chocolate derivates, soluble coffee, orange and passion-fruit juices and cookies to strengthen therefore its performance in the domestic market. These are products 
commercialized with the Native brand, but without the company's engagement in the production of the raw materials. At the end of 2008 there was the launch of the organic extra virgin olive oil. Considering these products and the organic sugar, in $1 \mathrm{~kg}$ packages and sachets, Native is currently present in over 7 thousand points of sale in Brazil, of which more than 3 thousand are supermarkets.

A new opportunity, which is being explored by Native since 2006, is the supply of neutral organic ethanol for the food, cosmetics and pharmaceutical industries, where it's used from the composition of drugs to the production of deodorants and colognes. Previously, all the ethanol deriving from the sugar processing -although organic - was marketed as conventional ethanol. In the domestic market, in 2006, Natura Cosmetics was the first demander of the product and even if in a small scale, Native has been exporting its ethanol since 2007.
Between 2004 and 2008 Native's sales grew more than four times, reaching $R \$ 76$ million. The sugar line is the most representative in the company's business model but one should highlight the rapid growth of the neutral organic ethanol's share in the company revenues, consolidated in the last two years analyzed, as well as the stabilizing of other products marketed under the Native brand, which begin to respond for approximately $32 \%$ of the company's sales in that period. The growth of these product lines result in a sales model more in balance between the domestic (40\%) and foreign (60\%) markets, since 2007. In 2008, with the commercialization of its organic sugar lines, Native sales summed $R \$ 51$ million, of which R\$ 45 million (88\%) corresponded to exports. Analyzing the period 2004-2008 the domestic market never represented more than $14 \%$ of the company sugar sales. It's therefore an exporting model that has already reached more than 60 countries throughout all of the continents. (Table I).

\begin{tabular}{c|c|c|c|c|c|c}
\hline \multirow{2}{*}{ Year } & \multirow{2}{*}{$\begin{array}{c}\text { Sales } \\
\text { (R\$ Million) }\end{array}$} & $\begin{array}{c}\text { Sugar } \\
(\%)\end{array}$ & $\begin{array}{c}\text { Ethanol } \\
(\%)\end{array}$ & $\begin{array}{c}\text { Others } \\
(\%)\end{array}$ & \begin{tabular}{c} 
Domestic (\%) \\
\cline { 3 - 7 }
\end{tabular} & $\begin{array}{c}\text { Foreign } \\
(\%)\end{array}$ \\
\hline 2004 & 17 & $92 \%$ & - & $8 \%$ & $20 \%$ & $80 \%$ \\
\hline 2005 & 28 & $93 \%$ & - & $7 \%$ & $17 \%$ & $83 \%$ \\
\hline 2006 & 51 & $89 \%$ & $6 \%$ & $5 \%$ & $21 \%$ & $79 \%$ \\
\hline 2007 & 64 & $68 \%$ & $27 \%$ & $5 \%$ & $40 \%$ & $60 \%$ \\
\hline 2008 & 76 & $68 \%$ & $27 \%$ & $5 \%$ & $40 \%$ & $60 \%$ \\
\hline
\end{tabular}

Table I. Native: Sales 2004-2008. Source: the authors

In 2009 it occupied approximately 14 thousand hectares of productive land with organic certification ${ }^{3}$, making Native the largest organic agriculture project in the world ${ }^{4}$, a fact that makes the study of this case quite significant. There are another I.3 thousand hectares undergoing conversion, of which 300 hectares are independent suppliers' areas. The price of organic sugar is detached from that of the conventional product, whose price varies up to $150 \%$ in one same year. Organic sugar price variation ranges about $15 \%$. The overprice average in comparison to the

3 Of the 14 thousand certified hectares, 6 thousand belong to Usina Santo Antônio.

4 In this analysis organic production projects in areas of cooperatives are not considered. conventional product is $40 \%$, with peaks above $100 \%$ in rare exceptions. The lowest difference ever experienced in Native's sales was 10\%, in a moment of peak in the price of the conventional product. According to the company, consumers accept to pay more for organic food because they perceive greatest value added to the product.

\section{Native Global Organic Sugar Market and Native's Share}

The International Sugar Organization shows no estimate of the international organic sugar market. An estimate of the size of this market, presented by Fernando Alonso in an interview for this research, is that in 2008 the market reached the mark of 265 thousand tons: Paraguay the main 
producer 110 thousand tons (42\%), followed by Brazil - 92 thousand tons (35\%), Argentina - 32 thousand tons (12\%), India - 15 thousand tons (5\%). All of the other producers responded in total for the 16 thousand remaining tons (6\%). This last group includes Cuba, Colombia, Thailand and Mexico. India and Argentina started playing a relevant role as from 2008.

Among the competing countries, Paraguay and Argentina show organic sugar production models based on input substitution and not on a complete change in the production process. This allows a high rotation of these markets' players: many businessmen decide to convert small areas to test the operation's profitability vis-à-vis the segment. As they don't advance in terms of productivity they're also unable to create solid commercial relations and end up returning rapidly to the conventional segment, or starting to pursue fair trade stamps. There are still many organic by default producers, those who produce in an organic manner because they have no access or resources to produce in the conventional manner. Such as in the substitution models these producers hardly reach a productivity advance.

In 2004 the volume of organic sugar commercialized by Native was of 15 thousand tons, of which $91 \%$ for the external market. In 2005 the sales more than doubled: 31 thousand tons, of which $94 \%$ for exports. In 2006, 42 thousand tons of organic sugar were commercialized, i.e., almost 3 times the volume commercialized in 2004 and $92 \%$ for the foreign market. The 48 thousand tons exported by Native in 2008 corresponded to $20 \%$ of the world organic sugar exports. The main destinations were: USA (45\%), European Union (40\%), Canada (10\%) and Japan (I\%). Of the remaining $4 \%$, Australia, South Korea and countries of the Middle East stand out.

Among the exports, $90 \%$ of the volume is destined to the food industry or to companies that resale the packaged product with self owned brands. In Japan Native provides for $60 \%$ of the industrial organic sugar demand. In Europe and the USA, the company's organic sugar reaches indirectly the industry through distributors such as Global Organics, British Sugar, Community Foods and Billington's Food Group, which commercialize Native's product under self owned brands such as Silver Spoon and Crazy Jacks. Among the industries that buy sugar from the company directly, one may highlight Nestle and Kraft that use the organic input

ISSN: 07I8-2724. (http://www.jotmi.org)

Journal of Technology Management \& Innovation (C) Universidad Alberto Hurtado, Facultad de Economía y Negocios although they don't offer certified products, and Danone who operates in the segment through the North American StonyField Farm, which produces natural yogurts and ice creams. Other important organic segment customers are the White Wave Foods, specialized in food and beverage, the Newman's Own Organics, chocolates and cookies, both based in the US, and Italy's Icam, manufacturing gourmet chocolates.

In respect to the characteristics demanded by the company's main customers - those in markets of developed countries -, the most important requirement for the product is the quality of the organic sugar. However, the organic production labels are considered decisive to access these markets, since they function as a company's distinguishing feature at the start of their customer relations. This differential is shown in a vote of trust to be tested thanks to the quality of the product and the company's reliability in fulfilling contracts. Because of the high rotation of companies in the organic production niche, reliability in fulfilling longer contracts is a valuable quality in this segment, as well as the building of long term customer relations.

\section{The Choice for Organic Production}

Initially, the Green Sugarcane Project was not pursuing the conversion to organic agriculture. As a coincidence, in 1995, the same year in which the productive system developed by the Green Sugarcane Project was applied in all the cultivated fields of Usina São Francisco, the company was consulted by North American Global Organics that was looking for organic sugar suppliers in Brazil. At that moment the demand for organic food was in full expansion and as organic sugar is a largely used base product in the food industry, it was accountable for one of the main bottlenecks for the industry's expansion. At the time suppliers of organic sugar were small and spread throughout several countries, i.e., there were no suppliers capable of fulfilling larger scale contracts. In addition, the disparity between organic sugars produced by the small producers was another worrying hurdle to the larger scale production of industrialized organic food.

After initial contacts, representatives of Global Organics indicated that the production process developed by the Green Sugarcane Project was close to the one required to obtain the certificate of organic production demanded by them. In face of this business opportunity Usina São 
Francisco was quick at deciding: from the beginning of conversations with Global Organics and the first shipping of sugar - already organic certified - it took two years. All stakes were therefore on the differentiation of this product through the organic certification, in other words, the bet was made on the un-commoditizing of its products, enabled by the certified organic production. The Native brand was launched in 1998 to represent the Green Sugarcane Project's philosophy in the organics segment, where organic sugar was the baseline for the first line of products. Between the then recently implemented production process developed within the Green Sugarcane Project and the requirements necessary for the achievement of the organic certification, adaptation took place more simply out in the sugar plantations, where the use of herbicides and synthetic fertilizers was definitely interrupted. In the industrial environment however, the adjustment occurred in a more complex way because of the need to mainstream management practices that are characteristic to the organic products' processing, such as for example production traceability requirements related procedures.

An aspect that should be highlighted refers to the ways in which the conversion of conventional to organic production can be achieved. Two are the paths. The first follows a logic of mere substitution of inputs, i.e., a chemical fertilizer is replaced by the outcome of a composting process or a herbicide is replaced by the weeding practice. The second path, reinvention, requires the complete change of the production system and pursues the full utilization of the crop's agricultural potential.

The Green Sugarcane Project trailed the latter before even knowing that the process destination would be the conversion to organic production, implying the realization of different pioneer and important innovations, both regarding agriculture and the industrial and commercial aspects. This decision itself is something new in the organic production environment. It did indeed involve carrying out important internal innovation with own personnel and the leadership in the innovation processes carried out by machinery and instruments suppliers. From the point of view of the technologies used, the agriculture and sugar and ethanol are sectors dependant on suppliers, according to the typology of Pavitt (1984) and Bell \& Pavitt (1993). As a rule, in supplier dependant sectors, technological innovations are developed by the machinery, equipment and productive input manufacturers and are transferred already inbuilt in capital goods and materials, such as harvesters, transportation equipment, pesticides and application equipment. As we will see, the conversion to organic agriculture at the Usina São Francisco did not follow this pattern, making this case emblematic and justifying its study as a unique case for it is a rare and revealing case, conditions that according to Yin (1994) would justify the use of unique case as a research strategy.

The possibility of access to the European and North American markets, both with raw and with processed sugar, encouraged the company to bet on organic production. The creation of the Native brand in 1998 is the main evidence. The first organic certification obtained was from the Farm Verified Organic (FVO) program, a private North American standard recognized by IFOAM. Due to the demand of a European customer, the Ecocert was also obtained. Today the Native organic sugar is also certified by JAS, the Japanese regulation, and has the IBD label for the domestic market. The management for so many distinct labels is made by adapting - for each requirement - to the strictest demands among all presented by the five environmental labels. In addition to the organic certifications, Usina São Francisco's ISO 9.001:2000 requirements based quality management system, is certified by an accredited agency as well.

\section{Innovations in the Sugarcane Production Process}

In 1986, when the Usina São Francisco started up the Green Sugarcane Project, its purpose was essentially that of developing a productive process that could avoid the burning of sugarcane for its harvest, a practice in place for centuries in the sugar and ethanol industry. It was hoped that with the end of the burning the company would reach: (i) a better use of the sugarcane crop's agricultural potentialities, (ii) higher productivity per hectare of sugarcane fields, in addition to (iii) major efficiency of the production process compared to the dependency on inputs external to the farms, such as synthetic herbicides and pesticides. On the overall, the Green Sugarcane Project demanded investments of US\$ 6 million and resulted in what Native managers understand as being "a new philosophy that revolutionizes the sugar production methods, involving since the preparation of the soil up to the special packaging and its exposure on the shelves of supermarkets". The implementation of raw sugarcane 
harvest demanded deep changes in the production process. The new system developed by the Green Sugarcane Project required biological control and soil conservation techniques' innovations.

As to biological controls, it was shown that it would be critical to adapt techniques to the sugarcane production process: specific enemies of pests started to be captured in the environment, reproduced in appropriate labs and introduced in the sugarcane fields by the millions. It was demonstrated that both the pest population as well as that of its enemies would have to be monitored and this process's information began to feed the next biological control and management initiatives. Two entomologic laboratories were created to produce insects that are natural enemies of the sugarcane borer. The biological control reduced from $11 \%$ down to $1.5 \%$ the infestation of crops and discarded the use of spraying chemicals - almost always imported, pollutant and less efficient than Native's employed alternative. In regards to the soil conservation there was the need to use vehicles and harvesters which would operate with high fluctuation conveyor belts and tires to avoid the soil's compacting. This equipment was developed in partnerships with agriculture equipment manufacturers. In addition to the mechanization the raw sugarcane production and harvest system developed within the scope of the Green Sugar Cane Project, contemplates the systematizing of areas for mechanical harvest; the adjustment of the varieties planted; the organic fertilizing; the phytosanitary treatment and the preparation of the soil.

Every year the soil receives green sugarcane straw - which is only possible because the harvest uses no fire - and Usina São Francisco's industrial organic effluents. These effluents, derived from physical and biological industrial processes are recycled and deposited on the ground with the function of returning nutrients and organic mater to the soil. In addition, at every 7 years the soil of plots is revolved and receives green fertilizers in a rotation with leguminous crops, to increase nutrient fixation in the soil and control of pests and spontaneous plants. Such procedure eventually allowed obtaining the organic certification for large extensions of sugarcane plantations, enabling Native to become the largest organic culture project at a world level. In this analysis one should also consider other benefits, environmentally related and resulting from the company's production practices: perceived biodiversity increase in the region and its surroundings and the impacts avoided thanks to the raw sugarcane cutting, both under the aspect of avoided GHG emissions - referring to a global benefit -, and in respect to issues linked to public health at the local level, such as the reduction of respiratory problems in the sugar plantations' surrounding population.

After almost tem years of experiences and innovations, in 1995 Usina São Francisco's total planted area was harvested without applying the sugarcane burning practice, also maintaining productivity higher than that of the conventional production process. As a result of these practices, the increase of biodiversity in the areas of native vegetation was perceived and measured, for example, by the greater number of animals in the surroundings of the production area. According to the Fauna Inventory conducted in 2003 by Embrapa Satellite Monitoring and by the NGO Ecoforça - Research and Development, 26 amphibians species, 230 of birds, 39 of mammals and 17 of reptiles were found, summing 312 vertebrates in an area of $79 \mathrm{~km}^{2}$.

It is important we highlight that it was only in 1995, nine years after the start of the Green Sugarcane Project that organic production emerged as a business alternative for the company, as we will describe in the following item. Native's production process contemplates also the reuse of bagasse to generate electricity. In 1987, the Usina São Francisco was pioneer in adding power to the system of the São Paulo Power and Light Company (CPFL) during the crops. Today about $300 \mathrm{KW}$ of power are destined to the CPFL, sufficient to service a town of 30 thousand inhabitants. The expectation that by eliminating burning the result would be a better use of the agricultural potentialities of the sugarcane crops and higher productivity per hectare in the sugarcane fields was confirmed: the company's productivity reached 104 tons of sugar per hectare in 2008 compared to an average of 84 tons presented by the conventional production in the State of São Paulo according to the Sugarcane Industry Institute (UNICA, 2006).

The technological innovations developed for the Green Sugarcane Project to produce organic sugar were, as from 2001 , transferred to other production processes, such as organic coffee and soybean, with the follow-up and approval of international certification organizations. The 
first organic coffee picking took place in $200 \mathrm{l}$ and organic soybean in 2005. In both cases, there are ongoing efforts in place to make these crops' productivity reach the averages of conventional plantations. Finally, as the sugarcane plantation management demands manual and mechanical techniques, and control methods require a distinct hand labor from that of conventional management, workers who previously did the manual sugarcane harvest were then retrained to perform these activities. It is worth underlining that the 3 considerations necessary to sustainable agriculture pointed out by Borch (2007), already shown in item 2, are observed in the Native case and that most importantly, they are not tackled as independent agendas.

\section{Opportunities and Challenges Perceived by the Entrepreneur}

At this moment there are great perspectives for the expansion of Native's participation in international markets, since there is a considerable repressed demand for organic sugar in developed countries and in smaller scale, in Brazil. The company believes that the premium prices should not be reduced in the short term. Thanks to this perception the company is preparing itself for an organic sugar production of 80 thousand tons p.a. The plantations can be in partnerships with agriculture producers, which would involve the transfer of production technology. However, two important movements are being seen in Native's strategy in the last years: the effort to increase the company's operations in the retail market and the pursuit for a product portfolio diversification, going beyond the sugar and ethanol chain.

As most of Native's revenue derives from sugar supply to major food companies, a recommended means would be to create a stamp identifying Native as supplier of end products' inputs to achieve a larger exposure with these companies' customers. Large companies would be interested in printing this stamp on their packages to inform the end customer about the rigor in the choice of its raw materials' suppliers. The positive social and environmental attributes of Native's production process would justify such decision. In addition, a new company, Biocycle, with the participation of the Balbo group, is dedicated to the increase, consolidation and development of the technology and of the production and commercialization of Polyhydroxybutyrate (PHB), the biodegradable plastic originating from sugar cane. Biocycle produces about 50 tons p.a. of $\mathrm{PHB}$, and once the production process is consolidated the forecast is a production of 30 thousand tons p.a. in the new plant.

\section{Conclusions}

The organic production system is one of the means to make agriculture sustainable, enabling this important human activity to contribute towards global society's sustainable development. Although there are so many doubts about organic agriculture the fact is that it is by now a reality as the data on the organic products' market show as well as the innumerable initiatives that support this activity, such as the certification, a valuable instrument to differentiate organic products from conventional ones, and government regulations arising in different countries. Brazil already has a regulatory framework in place for organic agriculture and a national compliance evaluation system is being built. The possibility of opening protected markets and achieving higher prices for organic products encourage the showing-up of producers with incomplete organic processes, based, for example, on the mere substitution of synthetic fertilizers for organic composts, hence the need for certificates that are reliable and legitimated by importers.

The certification is a final stage, the most important are the process technological innovations, applicable to the crop traits on the fields and that are able to raise productivity maintaining the vitality of the environment to continue producing ad infinitum, valuing the work force and promoting the surrounding community' development. These challenges are even greater for agri-industrial systems - such as the case we've studied -, because of the need for innovation in the industrial processes linked to innovations out in the fields. Native's case shows that these objectives may be reached, knocking down the widely rooted post-green-revolution agricultural environment idea that it's only possible to reach high productivity on the fields with the intensive use of inputs external to crops, such as pesticides and industrial fertilizers.

If on the one hand one nurtures the belief that scientific and technological breakthroughs will provide suitable answers to social and environmental problems, one has to recognize that the outcomes achieved by Native not only weaken such belief but also indicate that following this trail 
(or opening it up) could be a very profitable experience to those who dare do it. It's sufficient considering the analyzed company's access to the markets of developed countries, in a non-tariff barriers expansion scenario and of growing concern about social and environmental traceability along transnational production chains. One should acknowledge, however, that this path cannot be trailed alone. The Green Sugarcane Project counts on the involvement of research institutions such as Embrapa, Satellite Monitoring and the Technological Research Institute (IPT-USP), plus the collaboration with the State of São Paulo universities such as USP, UNESP and UNICAMP. Such partnerships were critical for the technological innovations that made large scale organic production and the company's products quality viable, in addition to the relations built with manufacturers, distributors and retailers focused at servicing consumers who value the organic product, be it because of the concerns about their own health or environmental problems.

The environmental and social aspects of the innovations that will be presented removed the commodity status from products and in addition to making them achieve access, also achieve a premium price that more than compensates the costs of the innovations showed. Thus the case shows that it is possible to innovate with profit and social and environmental concern simultaneously.

\section{References}

BELL, M., Pavitt, K. (1993). Technological Accumulation and industrial growth: contrast between developed and developing countries. Industrial and Corporate Change. 2(I), I57-210.

BORCH, K. (2007). Emerging technologies in favor of sustainable agriculture. Futures, 39(9), I.045-I.066.

BRASIL (2003). Law no. I083I, December 23 2003. Dispõe sobre a agricultura orgânica e dá outras providências. Diário Oficial da União, Brasília, DF.

CARSON, R. (2002). Silent spring. Boston: Mariner Books.

DAROLT, M. (2002). Agricultura orgânica: inventando o futuro. Curitiba: IAPAR.
EISENHARDT, K. (1989). Building theories from case study research. The academy of management review, 14(4), 532-550.

ELKINGTON, J. (200I). Canibais com garfo e faca. São Paulo: Makron Books.

European Environment Agency - EEA. Late lessons from early warnings:the precautionary principle 1896-2000. Copenhague, EEA, 200I.

Instituto de Tecnologia Social - ITS. (2004). Reflexões sobre a construção do conceito de tecnologia social. In: DE PAULO, A. et al. Tecnologia social: uma estratégia para o desenvolvimento. Rio de Janeiro, Fund. Banco do Brasil, 2004.

International Federation of Organic Agriculture Movements - IFOAM. (2009). Global Organic Agriculture: Continued Growth. IFOAM. http://www.ifoam.org/press/press/2008/Global_Organic_Ag riculture Continued Growth.php [Accessed September 29, 2010].

KEMP, R., Arundel, A. (1998). Survey indicators for environmental innovation. Indicators and Data for European Analysis - $\quad$ IDEA. http://www.step.no/old/Projectarea/IDEA/Idea8.pdf [Accessed September 29, 2010].

LELÉ, S. (I99I). Sustainable development: a critical review. World Development, 19(6), 607-62I.

MACEDO, I. (2005). A energia da cana-de-açúcar: doze estudos sobre a agroindustria da cana-de-açúcar no Brasil e a sustentabilidade. São Paulo: UNICA.

NORMAN, W.; Macdonald, C. (2004). Getting to bottom of triple bottom line. Business Ethics Quartely. I4(2), 243262.

PAVITT, K. (1984). Patterns of technical change: towards a taxonomy and a theory. Research Policy, I3(6), 343-73.

SACHS, I. (1993) Estratégias de transição para o século XXI: desenvolvimento e meio ambiente. São Paulo, Studio Nobel e Fund. de Desenvolvimento Administrativo. 
SHRIVASTAVA, P. (1995). Environmental technologies and competitive advantage. Strategic Management Journal, 16, 183-200..

THE ECONOMIST. (2006). Voting with your trolley: Can you really change the world just by buying certain foods?. The Economist, 38I (8507), 8I-83.

WORLD COMMISSION ON ENVIRONMENT AND DEVELOPMENT - WCED (199I). Nosso futuro comum. Rio de Janeiro: FGV.

YIN, R. Case Study Research: design and methods. Sage Publications, 1994. 